\title{
Una revisión del concepto de 'capital intelectual' y de las principales alternativas para su identificación y medición
}

\author{
Cecilia R. Ficco ${ }^{1}$
}

Recibido: 29 de octubre de 2019

Aprobado: 13 de noviembre de 2019

\begin{abstract}
Ficco, C. (2020). Una revisión del concepto de 'capital intelectual' y de las principales alternativas para su identificación y medición. Revista Activos, 18(1), 161-203. DoI: https://doi.org/10.15332/25005278/6162
\end{abstract}

\section{Clasificación JEL: J24}

\section{Resumen}

El presente trabajo tiene como objetivo analizar diferentes definiciones sobre el capital intelectual, con miras a identificar los rasgos definitorios del concepto y los distintos elementos y categorías que lo integran, así como a brindar una visión de los métodos y modelos que han alcanzado mayor difusión para su identificación y medición. Desde el punto de vista metodológico, se

1 Doctora en Ciencias Económicas, con mención Ciencias Empresariales por la Universidad Nacional de Córdoba (Argentina). Doctora en Ciencias Jurídicas, Económicas y Sociales por la Universidad de Burgos (España). Profesora asociada efectiva en la Facultad de Ciencias Económicas de la Universidad Nacional de Río Cuarto y profesora adjunta en el Instituto de Ciencias Sociales de la Universidad Nacional de Villa María. Docente-investigadora con categoría ir en el Programa Nacional de Incentivos. Directora y codirectora de proyectos y programas de investigación desde 2001. Correo electrónico: ceciliaficco@yahoo.com.ar 
ha realizado una investigación descriptiva y de tipo documental, concretada a través de la revisión y análisis de las contribuciones más significativas de los trabajos seminales en la temática y de las investigaciones más recientes que reflejan su evolución a través del tiempo. Se concluye que el capital intelectual tiene gran relevancia en el actual contexto, aunque se trata de una temática compleja y multifacética cuyo abordaje se encuentra aún inconcluso y en permanente evolución, lo que abre un importante campo para el desarrollo de investigaciones en esta línea.

Palabras clave: capital intelectual, capital humano, capital estructural, capital relacional, modelos de capital intelectual, revisión.

\title{
A Review of the Concept of Intellectual Capital and the Main Alternatives for its Identification and Measurement
}

\begin{abstract}
The aim of this paper is to analyse different definitions of intellectual capital, with a view to identifying the defining features of the concept and the different elements and categories that comprise it, as well as to provide an overview of the methods and models that have reached the widest diffusion for its identification and measurement. From a methodological point of view, a descriptive and documentary research has been carried out through the review and analysis of the most significant contributions of seminal works in the subject and the most recent research, which reflects their evolution over time. The conclusion is reached that intellectual capital has great relevance in the current context, although it is a complex and multifaceted issue whose approach is still unfinished and constantly evolving, which opens an important field for the development of research in this line.
\end{abstract}

Keywords: intellectual capital, human capital, structural capital, relational capital, intellectual capital models, review. 


\section{Introducción}

En una fase histórica conocida como economía del conocimiento, el mundo actual asiste a un proceso acelerado y complejo de cambio económico cuyo conocimiento se ubica en el centro del escenario cuando se trata la creación de valor (Torrent, 2016).

Esta nueva economía puede entenderse como una evolución de la economía industrial, centrada en el empleo de recursos materiales, hacia una economía en la que el conocimiento pasa a ser un elemento clave del crecimiento y el desarrollo económico. Este planteamiento deriva "de la aportación precursora de Marshall (1890) sobre aquel como cuarto factor o agente de producción. así como de las contribuciones que le siguieron gracias a las ideas de Drucker (1965) y Machlup (1980), entre otros" (Bueno, Salmador y Merino, 2008, p. 44).

El conocimiento se ha convertido, así, en el recurso estratégico por excelencia, tanto a nivel macroeconómico como a nivel de las empresas y otras organizaciones. Esto ha determinado que la generación de riqueza se encuentre asociada, fundamentalmente, a elementos de carácter intangible (Azofra et ál., 2017; Xu y Wang, 2018; Zambon, 2017).

Estos elementos intangibles, directamente vinculados con el conocimiento, son habitualmente incluidos bajo la denominación de capital intelectual. Esta es una expresión de carácter amplio, en la medida que engloba una gran variedad de conceptos, entre los que se incluyen el conocimiento de los empleados y otros aspectos relacionados con el capital humano, las rutinas organizativas, la calidad de los procesos, productos y servicios de la empresa, su capital tecnológico, la capacidad de innovación, las relaciones con los clientes y con otros stakeholders, entre otros (Ficco, 2019).

No obstante, y aun cuando el término capital intelectual (CI) se encuentra ampliamente difundido, este es empleado con diferentes acepciones y no se ha llegado todavía a una definición de aceptación unificada. 
Ahora bien, el nuevo entorno económico y productivo que configura la economía del conocimiento tiene profundas implicaciones para la contabilidad, la cual utiliza como medio de difusión de la información contable los estados financieros tradicionales. Estos han sido desarrollados para una economía industrial (Cañibano, 2007) y con base en normas que no permiten brindar una imagen adecuada de la situación financiera de las empresas en el actual contexto.

En efecto, la postura que ha predominado en los principales organismos emisores de normas contables ha sido conservadora con relación a los activos intangibles, siendo, en general, restrictiva en lo que respecta a su inclusión en los estados financieros (Cañibano y Gisbert, 2006; Ficco, 2019; Lev, 2005; López et ál., 2013; Pastor et ál., 2017; Pérez y Tangarife, 2013; Sharma, 2012; Zambon, 2017). Esto ha dado lugar a que muchos importantes elementos basados en conocimiento - habitualmente designados como $\mathrm{CI}$ - queden fuera de dichos estados, por no cumplir con los requisitos previstos para su reconocimiento contable.

Frente a ello, y como una forma de paliar esta carencia de la contabilidad financiera, se han ido diseñando distintos métodos y modelos que brindan información sobre el cr, lo que permite su identificación y medición. Sin embargo, la variedad de propuestas elaboradas es muy amplia y tampoco se ha alcanzado un consenso que permita indicar cuáles son las alternativas más apropiadas para efectuar tal medición.

Este es el marco problemático en el que se inserta el presente estudio, que tiene como objetivo analizar diferentes definiciones desarrolladas para el CI, con vistas a identificar los rasgos definitorios del concepto junto a los distintos elementos y categorías que lo integran, y también brindar una visión de los métodos y modelos que han alcanzado mayor difusión para su identificación y medición.

Desde el punto de vista metodológico, se ha realizado una investigación descriptiva y de tipo documental, concretada a través de la revisión y análisis de la literatura más relevante en la materia. Se ha adoptado un enfoque 
integrador para la revisión, por lo que en la selección de los trabajos analizados se han considerado las aportaciones de autores de diferentes países, e incluye tanto las de aquellos que han sido pioneros y creadores de los trabajos seminales en la temática, como las que surgen de investigaciones más recientes y que reflejan su evolución a través del tiempo.

De este modo, y en consonancia con el enfoque amplio e integrador adoptado, se han consultado diversos recursos de información y bases de datos para la búsqueda de trabajos. Concretamente, las bases de las que se obtuvieron los trabajos seleccionados son las siguientes: Dialnet, Ebscohost, Elsevier, Emerald, IEEE Xplore Digital Library, Redalyc, Taylor \& Francis y Wiley Online Library. También, se ha elegido un rango temporal amplio para el análisis, específicamente, las últimas tres décadas, por ser este el periodo en el que se produce el origen y la evolución del fenómeno del CI en el ámbito empresarial (Dumay et ál., 2018; Martín et ál., 2010).

Este trabajo se desarrolla en tres partes. En la primera de ellas, se recogen distintas definiciones de CI, que se analizan en el marco del recorrido evolutivo del concepto y atendiendo a la perspectiva o enfoque al que principalmente se asocian; su revisión ha permitido configurar las características definitorias del concepto. Seguidamente, se presenta la categorización de los elementos que constituyen el cI, prestando una especial y exhaustiva atención a la caracterización y composición de cada categoría. En la tercera parte se exponen los métodos y modelos para su identificación y medición, que se presentan clasificados con base en eñ clásico criterio que distingue entre los que realizan mediciones en unidades monetarias de aquellos que son no financieros. Finalmente, se exponen las conclusiones de este estudio.

\section{Conceptualización de capital intelectual: revisión y discusión de algunas definiciones}

Tal como se ha señalado en la introducción, no existe un consenso en torno al concepto de ci, y más bien sí distintas definiciones con diferentes alcances en cuanto a los elementos que involucra y términos disímiles para referirlo. 
Esta diversidad tiene que ver con el hecho de que se trata de un concepto complejo y multifacético, que se ha ido desarrollando con aportes desde múltiples disciplinas y perspectivas y que todavía puede considerarse, tal como indica Ilyin (2014), un concepto emergente y de rápida evolución.

La primera publicación del término cr la realizó John Kenneth Galbraith en 1969 (Bontis, 1998), al referirse a este como acción intelectual, más que mero conocimiento o puro intelecto. No obstante, en la literatura económica, el concepto fue introducido por primera vez por List, en 1841, quien lo define como aquél referido a las naciones y que surge en virtud de la acumulación de descubrimientos, invenciones, esfuerzos, entre otros, de las generaciones precedentes (Bueno et ál., 2008). El concepto tiene, de este modo, raíces económicas, lo que permite explicar la denominación de 'capital' (Martín et ál., 2010) que muchos autores cuestionan (Dean y Kretschmer, 2007; Lentjušenkova y Lapina, 2016)².

Sin embargo, con el surgimiento de la sociedad del conocimiento cobra relevancia el cr y se produce lo que podría llamarse el auge inicial del concepto, el cual se difunde rápidamente en los distintos ámbitos académicos y profesionales. En este marco, uno de los hechos que más fuertemente se asocian al surgimiento del ci como un concepto nuevo es la búsqueda de explicaciones a las grandes diferencias surgidas entre el valor de mercado y el valor contable de algunas importantes empresas cotizantes en la Bolsa de Nueva York durante las décadas de los ochenta y noventa del siglo pasado (Ficco, 2018). En esta época, autores como Edvinsson y Malone (1997) denominan cr a la diferencia entre el valor de mercado y el valor contable

2 Estos cuestionamientos derivan de que la idea de capital convierte a los elementos que integran el CI en algo estático, separable de los individuos o grupos dentro de los cuales residen y con posibilidad de ser valorados independientemente de ellos y de manera previa a su aplicación, lo que impone grandes restricciones al concepto (Dean y Kretschmer, 2007). En la misma línea, Lentjušenkova y Lapina (2016) señalan que la concepción de 'capital', que se deriva de la teoría económica clásica, hace referencia a un recurso que es propiedad de la organización y que se utiliza para producir bienes y prestar servicios, y que esta concepción también se asocia a una perspectiva estática que no refleja la verdadera naturaleza del cr a nivel organizacional. 
(Simó y Sallán, 2008), de modo que reconocen la existencia de una serie de activos, de naturaleza intangible y derivados de la puesta en acción de actividades basadas en conocimiento, que el mercado valora y que no están reflejados en los estados financieros de las empresas ${ }^{3}$.

Esta perspectiva financiera del concepto, que alude a la diferencia valorativa de las empresas en la economía del conocimiento (Bueno y Murcia, 2018), es una de las acepciones más usadas del término Cr. Bajo esta perspectiva, se le considera sinónimo de activos intangibles "ocultos", por aludir a elementos que no aparecen en los estados financieros de las empresas. No obstante, ha sido empleado también con otras acepciones, como sinónimo de activos intangibles en general, como sinónimo de capital humano y como sinónimo de plusvalía, tanto adquirida como internamente generada (Sierra y Rojo, 2001).

La variedad de acepciones, así como de disciplinas y perspectivas desde las cuales se ha abordado el concepto de CI, ha dado lugar también al empleo de distintos términos para referirlo. Así, tal como señalan Edvinsson y Malone (1999), se han utilizado como términos equivalentes a cr: capital de conocimientos o activos de conocimiento - fundamentalmente en el campo de la economía一, activos inmateriales o intangibles, activos invisibles, activos ocultos, así como también, la diferencia entre el valor de mercado de la empresa y su valor en libros.

Con relación a las definiciones de cr, muchas de ellas se han desarrollado en torno a la perspectiva financiera del concepto antes referida, en cuyo marco se asocia al ci con los activos intangibles ocultos de las empresas.

3 Esta brecha entre el valor contable y el valor de mercado de las empresas cotizantes en los mercados de valores persiste en la actualidad. Así, en un estudio recientemente realizado para el mercado de capitales argentino (Ficco, 2018), se detecta que el valor contable de empresas cotizantes es claramente inferior a su valor de mercado. Específicamente, el patrimonio neto promedio por acción ni siquiera alcanza al $40 \%$ del precio promedio por acción, lo que revela que más del $60 \%$ del valor de mercado de las empresas cotizantes argentinas no tienen reconocimiento en los estados financieros, siendo esa proporción coincidente con la que presentan Kimouche y Rouabhi (2016) para el Reino Unido. 
En esta línea se encuentran las definiciones aportadas por Edvinsson y Malone (1997), Roos et ál. (1997), Euroforum Escorial (1998), Ordóñez de Pablos (2003) y Forte et ál. (2017).

Así, Edvinsson y Malone (1997) describen al cr como el estudio de las raíces del valor de la empresa, la medida de los factores dinámicos ocultos bajo sus instalaciones y productos, e indican que estaría integrado por la posesión de conocimiento, experiencia aplicada, tecnología organizativa, relaciones con clientes y destrezas profesionales que le otorgan a la empresa una ventaja competitiva en el mercado. Roos et ál. (1997), con una visión más generalizada, lo definieron como la suma de activos ocultos de una compañía que no están totalmente capturados o representados en el balance de situación. Con un criterio similar, que también relaciona el concepto de CI con el concepto contable de activos intangibles, Euroforum Escorial (1998), señala que el cr puede ser también entendido como el conjunto de activos intangibles de una organización que, pese a no estar reflejados en los estados financieros tradicionales, en la actualidad, el mercado percibe que generan valor o tienen potencial de generarlo en el futuro.

Por su parte, Ordóñez de Pablos (2003) plantea expresamente que el CI es la diferencia entre el valor de mercado de la empresa y su valor contable, y que está formado por los recursos basados en el conocimiento lo cuales, pese a no estar registrados en los estados financieros, contribuyen a la ventaja competitiva sostenible de la firma. En el mismo sentido, Forte et ál. (2017), indican que el cı puede considerarse como un "valor oculto" significativo que puede ser medido por la diferencia entre el valor de mercado de la empresa y su valor en libros.

Autores como Brooking (1996), Sveiby (1997), Bontis et ál. (1999), Lev (2001), Cañibano et ál. (2002) y Kujansivu y Lönnqvist (2007) brindan, en cambio, definiciones que asocian el concepto de CI al de intangibles, o activos intangibles, en general. Así, Brooking (1996) considera al cI como aquella combinación de activos intangibles que permiten a la empresa funcionar y que está compuesto por activos de mercado, activos de propiedad intelectual, activos centrados en lo humano y activos de infraestructura. 
Sveiby (1997) lo definió como la combinación de activos intangibles que generan crecimiento, renovación, eficiencia y estabilidad en la organización, e indica que se trata de activos invisibles que incluyen la competencia de los empleados, la estructura interna y la externa.

Por su parte, Bontis et ál. (1999) lo definen como una simple colección de recursos intangibles y sus flujos. Para Lev (2001), representa las relaciones principales, generadoras de activos intangibles, entre innovación, prácticas organizativas y recursos humanos. De acuerdo con Cañibano et ál. (2002), el CI es la combinación de los recursos humanos, organizativos y relacionales de una empresa y abarca todas las formas de elementos intangibles, tanto aquellos formalmente poseídos como aquellos que son informalmente movilizados, que, al ser utilizados por la empresa, en adecuada conexión, generan valor para la misma. Del mismo modo, Kujansivu y Lönnqvist (2007) sugieren que el ci está constituido por todos los activos inmateriales y no físicos, que son especialmente importantes en una industria intensiva en conocimiento.

Stewart (1998), al igual que Edvinsson y Malone (1997) y Ordóñez de Pablos (2003), influenciados por la visión de la empresa basada en recursos (Barney, 1991; Wernerfelt, 1984), conciben el cI integrado por todos aquellos recursos que pueden proporcionar a la empresa una ventaja competitiva. Según Stewart (1998), el cI es la suma de todos los conocimientos que poseen todos los empleados de la empresa y que le dan a esta una ventaja competitiva; se trata de material intelectual (conocimiento, información, propiedad intelectual, experiencia) que puede ser utilizado en la creación de riqueza.

Puede apreciarse también que en esas mismas definiciones (Edvinsson y Malone, 1997; Ordóñez de Pablos, 2003; Stewart, 1998), el término ci está estrechamente vinculado al concepto de 'conocimiento', lo cual es acorde con la visión de la empresa antes mencionada, si se considera, tal como afirma Nonaka (1991), que el conocimiento es la única fuente duradera de ventaja competitiva. 
Sin duda, los esfuerzos realizados por vincular las nociones de conocimiento e intangibles constituyen otro hito importante que se produce en la década de los noventa, dentro de lo que puede considerarse como la primera fase de evolución del ci como concepto nuevo. En esta etapa, caracterizada por el hecho de que los principales aportes a la temática proceden de la práctica profesional, del mundo de la empresa y de la consultoría, así como de ciertos académicos e instituciones de investigación que actúan fundamentalmente desde el punto de vista de la práctica empresarial (Martín et ál., 2010), esos esfuerzos quedan justificados ante la trascendencia de un intangible clásico en las empresas, como es la innovación (Castilla y Ruiz, 2014) y la preocupación por encontrar las herramientas para su adecuada gestión.

Ross et ál. (2001), Viedma (2007), Carlucci y Schiuma (2007), Martín et ál. (2010), Kianto et ál. (2013), y Sardo y Serrasqueiro (2018) también han definido al cr a través de su asociación con el concepto de conocimiento. Los primeros consideran que el cr es la suma del conocimiento de los miembros de la organización y de la interpretación práctica de este conocimiento, es decir, de sus marcas, patentes y procesos. Añaden también que es cualquier cosa que puede crear valor, pero que no se puede tocar con las manos. Viedma (2007) define al ci como el conocimiento y otros intangibles que crean o producen valor en el presente, y aquellos conocimientos y otros intangibles que pueden crearlo o producirlo en el futuro. Carlucci y Schiuma (2007) lo consideran como un concepto holístico que involucra las diferentes categorías de activos de conocimiento organizacionales. Finalmente, Martín et ál. (2010) lo definen como el conjunto de recursos intangibles y capacidades, basados en información y conocimiento, de carácter tanto individual como colectivo/social, que puede ser fuente del logro y sostenimiento de la ventaja competitiva.

Por su parte, Kianto et ál. (2013) postulan que el cI comprende los valiosos recursos basados en el conocimiento y las actividades de gestión relacionadas con ellos, mientras que Sardo y Serrasqueiro (2018) indican que representa las actividades y procesos basados en el conocimiento que 
contribuyen a la innovación, a la creación de valor y al logro de ventajas competitivas y beneficios futuros para las empresas, al agregar valor para todos sus stakeholders.

En lo que respecta a estas definiciones, en las que aparece expresamente el vínculo entre CI y conocimiento, siguiendo lo señalado por Lentjušenkova y Lapina (2016), el concepto de cI es más amplio que el de conocimiento, pues es este último un componente del primero. Además, y como fruto de la visión dinámica del ci que se ha desarrollado en la última década, este es visto como un concepto más abarcador que incluye no solo al conocimiento, entendido como recurso, sino también a su gestión y a su rol en las distintas operaciones que realiza la empresa, tal como queda patente en las definiciones de Kianto el ál. (2013) y de Sardo y Serrasqueiro (2018).

Bueno et ál. (2008) definen al ci como la acumulación de conocimiento que crea valor y que está compuesta por un conjunto de activos de naturaleza intangible o recursos y capacidades basados en conocimiento, que cuando se ponen en acción, en combinación con el capital físico o tangible, es capaz de generar ventajas competitivas. Gogan et ál. (2014) lo conceptualizan como la forma en que las organizaciones crean valor a través de sus recursos monetarios, no monetarios, físicos y no físicos, que tienen que ser identificados (conocidos), utilizados (explotados), medidos (evaluados, controlados) y gestionados adecuadamente. Finalmente, Lentjušenkova y Lapina (2016) lo definen como el activo de la organización que incluye el capital humano, los procesos comerciales, las tecnologías de información y comunicación, y los activos intangibles que pueden ser transformados en valor tangible e intangible.

Aparece, claramente, en estas tres últimas definiciones, al igual que en otras anteriormente referidas (Cañibano et ál., 2002; Euroforum Escorial, 1998; Ross et ál., 2001; Sardo y Serrasqueiro, 2018; Stewart, 1998; Viedma, 2007), la idea de que el ci le permite a la empresa crear valor en el presente y le otorga potencial para crearlo en el futuro. En esta línea, es importante resaltar que, en las definiciones más recientes, emerge una 
expresa alusión a una concepción de valor más holística, que considera tanto la creación de valor financiero como no financiero (Lentjušenkova y Lapina, 2016), así como también, la idea de creación de valor para el conjunto de stakeholders (Sardo y Serrasqueiro, 2018) con quienes la empresa entabla relaciones. Se destaca, además, tanto en las definiciones de Bueno et ál. (2008) como de Gogan et ál. (2014), la trascendencia que tienen, en el proceso de creación de valor que conlleva el cI, no solo los recursos intangibles, sino también los de naturaleza física o tangible.

Puede apreciarse, de este modo, que existe una extensa literatura en torno al concepto de CI, aunque no se ha llegado aún a una definición de aceptación generalizada. Se trata, más bien, de un concepto en evolución que se ha configurado y se sigue desarrollando desde diferentes enfoques y perspectivas. No obstante, sí es posible identificar una serie de aspectos o características que están presentes en gran parte de los conceptos elaborados y que pueden considerarse definitorios del cI (figura 1):

- Conjunto de elementos intangibles (recursos, capacidades y actividades) relacionados entre sí,

- entre los que destaca el conocimiento disponible, tanto a nivel individual como organizativo,

- que están en cierta medida "ocultos", por no estar en los estados financieros elaborados en base a la normativa vigente y

- que permiten a la empresa funcionar, en combinación con los demás recursos inherentes a la misma,

- de manera que es fuente de ventaja competitiva y de creación de valor. 
Una revisión del concepto de 'capital intelectual'y de las | REVISTA ACTIVOS 173 principales alternativas para su identificación y medición

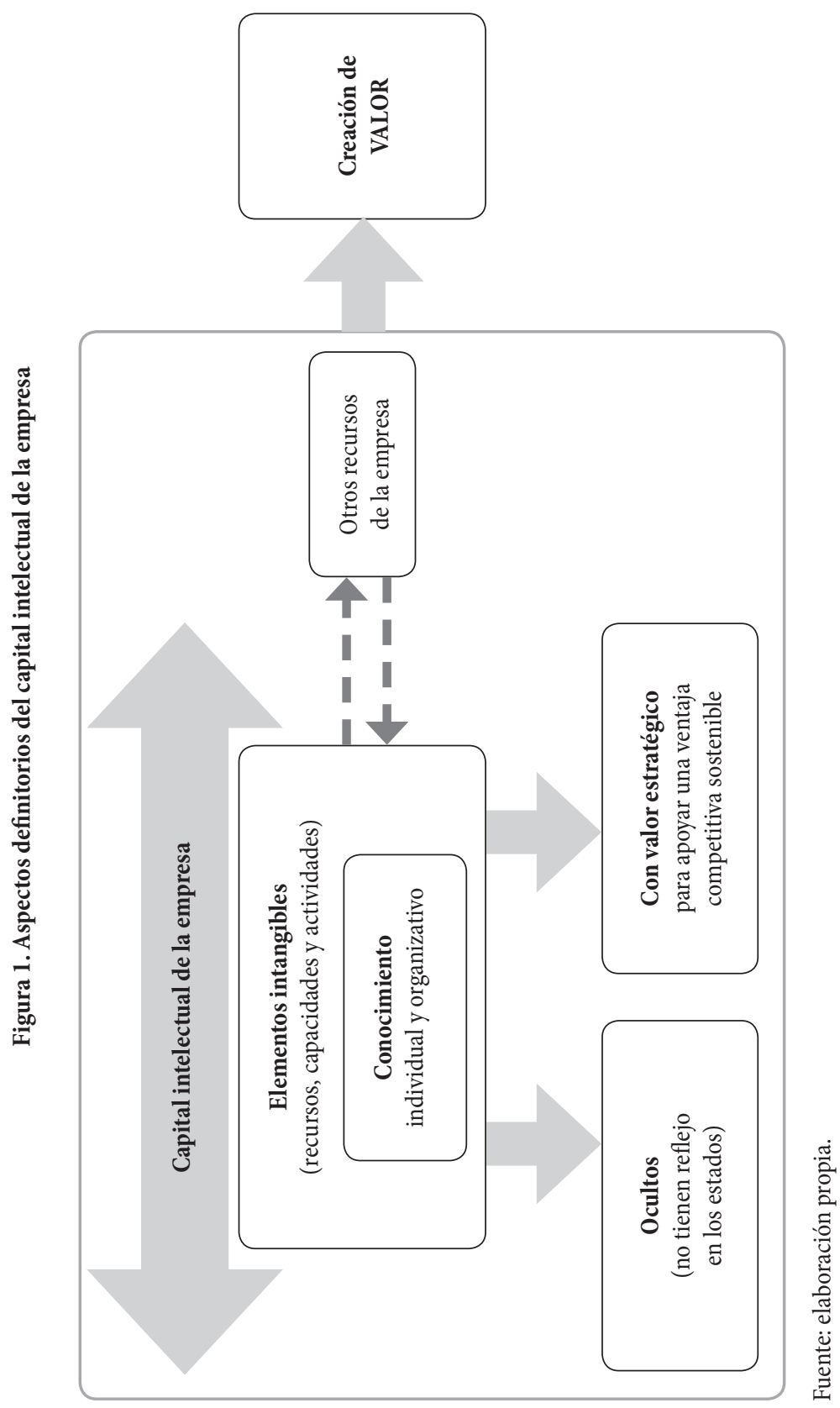




\section{Elementos integrantes del capital intelectual y su clasificación}

La revisión de conceptos antes presentada permite advertir una serie de elementos que, en forma particular, los diferentes autores han ido explicitando como integrantes del cr. Entre ellos figuran el conocimiento, la experiencia, las destrezas y las competencias de los empleados, las tecnologías y los procesos organizativos, y las relaciones con los clientes.

Se trata, pues, de elementos de diversa índole, pero que pueden agruparse en una serie de categorías que permiten elaborar clasificaciones del Cr. Una de las primeras clasificaciones aportadas es la Edvinsson y Malone (1997), quienes proponen que el CI engloba dos dimensiones: el capital humano y el capital estructural. Y, aunque muchas otras propuestas de clasificación se han lanzado, involucrando abundantes denominaciones y tipologías, las dos categorías identificadas por Edvinsson y Malone (1997) han sido clave en el resto de las propuestas, de modo tal que en la actualidad existe un amplio consenso en lo atinente a la clasificación del CI en: capital humano, capital estructural y capital relacional (Bontis, 1998; Bueno et ál., 2008; Cañibano et ál., 2002; Ficco, 2020; Ginesti et ál., 2018; Martín et ál., 2010; Ross, 2017;), tal como se esquematiza en la figura 2. 
Figura 2. Dimensiones del capital intelectual.

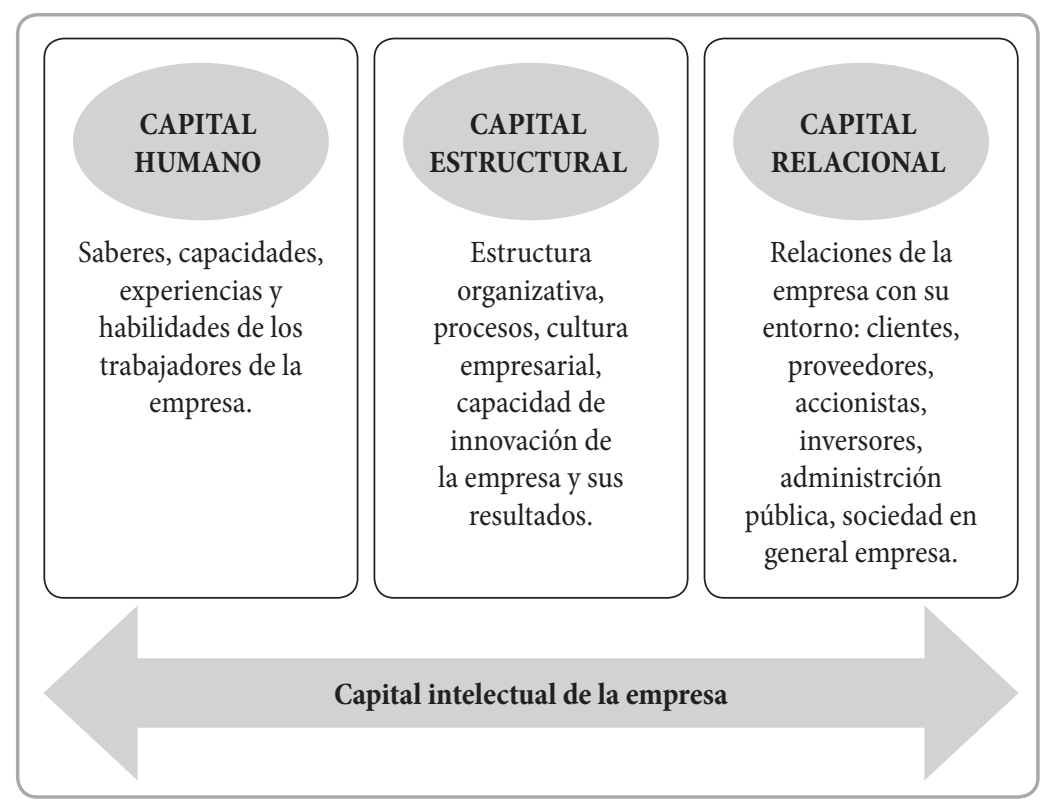

Fuente: elaboración propia.

\section{Capital humano}

El capital humano, también denominado por Brooking (1996) como activos centrados en lo humano, constituye una dimensión clave del cI. Es considerado el elemento primario del ci y la fuente más importante de ventaja competitiva sostenible (Cabrita y Bontis, 2008; Edvinsson y Malone, 1997; Nonaka y Takeuchi, 1995; Sveiby, 1998), por ser un factor fundamental para la empresa cuya carencia condicionaría negativamente el resto de las actividades que generan valor para la misma (Edvinsson y Malone, 1999; Smriti y Das, 2018; Tyskbo, 2019).

Se trata del capital que reside en los miembros de la organización, en sus trabajadores y directivos. Para Edvinsson y Malone (1997) "el capital humano es una combinación de conocimientos, habilidades, experiencia, 
inventiva y capacidades individuales de los trabajadores de una empresa, siendo ésta incapaz de apropiarse del mismo".

Aparece aquí, además de los distintos elementos que involucra, la idea que también comparten otros autores respecto a que el capital humano es aquel conocimiento que presenta dificultades para ser retenido por la empresa, ya que la misma lo pierde cuando sus empleados la abandonan. Esta idea está fuertemente plasmada en la conceptualización que aportan Cañibano et ál. (2002), en tanto indica que el capital humano está integrado por el conocimiento que el empleado se lleva cuando abandona la empresa.

En este sentido, el capital humano estaría integrado por conocimiento tácito, el cual, de acuerdo con Nonaka (1991), resulta difícil de formalizar y, por ello, de comunicar a otros y consiste en modelos mentales, creencias y perspectivas difíciles de articular. Así también lo plantea Bontis (1998), al indicar que el conocimiento tácito caracteriza al capital humano de la organización. Siguiendo a Hudson (1993), el capital humano también puede ser definido como la combinación de cuatro factores: la herencia genética, la educación, la experiencia y las actitudes frente a la vida personal y profesional.

Sveiby (1998) se refiere a esta dimensión como "competencias individuales" de los trabajadores, e indica que se trata de la capacidad de las personas para actuar en diversas situaciones. Esas competencias incluyen habilidades, educación, experiencia, valores y habilidades sociales.

Cañibano et ál. (2002) aseguran que el capital humano incluye los saberes, las capacidades, experiencias y habilidades de las personas que integran la organización y, como ejemplos de elementos integrantes de este, menciona los siguientes: la capacidad para innovar, la creatividad, el saber hacer y la experiencia previa, la capacidad para trabajar en equipo, la flexibilidad del empleado, la capacidad de negociación, la motivación, la satisfacción, la capacidad para aprender, la lealtad, etc., así como su nivel educativo y la titulación académica. 
Roos et ál. (2001) han agrupado estos distintos elementos en tres categorías. Según los autores, el valor del capital humano se origina a partir de la competencia, la actitud y la agilidad intelectual de los empleados, donde la competencia comprende conocimiento, destrezas, habilidades y saber hacer. La actitud incluye el valor generado por el comportamiento que el empleado manifiesta hacia su trabajo, y la agilidad intelectual representa la habilidad para innovar y cambiar prácticas, reflexionar sobre los problemas y llegar a soluciones innovadoras.

\section{Capital estructural}

De acuerdo con Edvinsson y Malone (1997), el capital estructural es la infraestructura que incorpora, forma y sostiene el capital humano, de modo que alienta al factor humano a crear y compartir su conocimiento. Bontis (1998) lo define como aquellos mecanismos y estructuras de la organización que pueden servir de soporte a los empleados para optimizar su rendimiento intelectual y, con ello, el rendimiento empresarial en su conjunto.

De esta manera, el capital estructural da cuerpo al capital humano, le sirve de infraestructura y soporte, pero a la vez lo potencia, con lo que permite su mejor aprovechamiento, revelando, además, la aptitud de la organización para captar, integrar, almacenar y trasmitir material intelectual (Ochoa et ál., 2010).

El capital estructural es, esencialmente, conocimiento que la organización ha podido internalizar y que, por tanto, queda incorporado en su propia estructura y procesos internos, aun cuando los empleados abandonan la empresa. Por ello, el capital estructural, a diferencia del humano, sí puede ser propiedad de la empresa.

Esta idea de conocimiento incorporado a la organización ha sido manifestada por varios autores, entre ellos Edvinsson y Malone (1997), Ross et ál. (1997) y Cañibano et ál. (2002), tal como la que exponen Cañibano et ál. (2002) al indicar que "el capital estructural se define como el conjunto 
de conocimientos que permanece en la empresa al final de la jornada laboral" (p. 19).

Bontis et ál. (2000) incluyen dentro del capital estructural todas las formas en las que pueda estar incorporado el conocimiento dentro de la organización, distintas de la posesión de conocimiento por parte de los empleados, lo que involucra bases de datos, manuales de procedimientos, estrategias, rutinas, entre otras.

De acuerdo con Cañibano et ál. (2002), el CI comprende las rutinas organizativas, los procedimientos, sistemas, cultura, bases de datos, entre otros. Lo integra, por ejemplo, la flexibilidad organizativa, el servicio de documentación, el uso generalizado de tecnologías de la información, la capacidad organizativa de aprender, etc. Con esto, algunos de ellos pueden protegerse legalmente y convertirse en derechos de propiedad intelectual o industrial, como los derechos de autor o las patentes.

Muchos de los elementos antes referidos permiten vincular al capital estructural con la idea de conocimiento explícito, que, de acuerdo con Nonaka (1991) representa conocimiento formalizado que puede ser comunicado y compartido fácilmente a través de documentos, bases de datos, manuales operacionales, especificaciones de un producto, fórmulas, programas informáticos, entre otros.

La amplia variedad de componentes del capital estructural ha motivado la distinción de diferentes dimensiones integrantes de este. Así, Edvinsson y Malone (1997), y Ross et ál. (2001) diferencian entre capital organizacional y capital de renovación y desarrollo; Bueno (2003), al igual que Martín et ál. (2010) y Scafarto et ál. (2016), distinguen dos subconjuntos: el capital organizativo y el capital tecnológico. Brooking (1996), aunque no habla de capital estructural, diferencia como componentes del ci los activos de propiedad intelectual y a los activos de infraestructura. Finalmente, Bontis (1999) diferencia el componente tecnológico de las competencias integradoras que constituyen el capital estructural. 
Sin embargo, más allá de las divergencias en las tipologías que integrarían el capital estructural y en las denominaciones otorgadas a aquellas, en general, es posible distinguir dos tipos de elementos en su interior. Tal como lo expresan Ochoa et ál. (2010), el capital estructural incluye, por un lado, los elementos internos actualmente operativos en la organización, como la infraestructura, los procesos y la cultura empresarial, y, por otro, los elementos que aludirían a la capacidad de renovación de la empresa y a los resultados de la innovación en forma de derechos comerciales protegidos, propiedad intelectual, etc.

En esta misma línea, Martín et ál. (2010) aluden a los elementos del primer grupo refiriendo al conocimiento colectivo existente en la organización que se almacena, recupera, gestiona y transfiere vía cultura organizativa, rutinas y estructura organizativas, e incluye también a las capacidades en tecnologías de la información y las comunicaciones. Los autores también describen al segundo conjunto de elementos como aquellos vinculados al conocimiento colectivo de carácter técnico-científico que incluye aspectos como los esfuerzos en I+D, la dotación de infraestructura tecnológica y la propiedad intelectual e industrial.

\section{Capital relacional}

El capital relacional está fundamentalmente asociado al valor que generan las relaciones que la empresa entabla con el exterior. Así, Cañibano et ál. (2002) indican que "por capital relacional se entiende el conjunto de recursos ligados a las relaciones externas de la empresa con sus clientes, proveedores de bienes, servicios o capital o con sus socios de I+D" (p. 19). De esta forma, el capital relacional tiene un alcance más amplio que el que le atribuyen Edvinsson y Malone (1997), quienes lo asimilan a las relaciones que la empresa establece con sus clientes.

Roos et ál. (2001), aunque al igual que los autores citados consideran al capital relacional como parte integrante del capital estructural, señalan que las principales fuentes de este tipo de capital procederían, entre otros 
stakeholders, de los clientes, suministradores, empresas participantes en alianzas y accionistas, y colectivos. Con ellos se pretende, en términos generales, cultivar relaciones de largo plazo para el intercambio de información y productos, basadas en el beneficio mutuo.

Cañibano et ál. (2002), al definir este tipo de capital, indican que "comprende tanto las relaciones de la empresa con terceros (inversores, acreedores, clientes, proveedores, etc.), como las percepciones que estos tienen de la compañía", siendo ejemplos de esta categoría "la imagen, la lealtad y la satisfacción de los clientes, los pactos con los proveedores, el poder comercial, la capacidad de negociación con instituciones financieras, con reguladores, etc." (p. 19).

Bontis (1999), al conceptualizar el capital relacional pone énfasis en el conocimiento generado en estas relaciones e indica que se trata del "conocimiento incorporado en las relaciones establecidas con el entorno exterior" (p. 444). En el mismo sentido, Ginesti et ál. (2018) indican que representa el conocimiento existente en una organización que permite crear relaciones sólidas con su ámbito externo.

Brooking (1996) hace referencia a esta dimensión del ci como activos de mercado, y los define como el potencial que posee una organización en virtud de sus recursos intangibles relacionados con el mercado. Por su parte, Sveiby (1998) la denomina "estructura externa"; consiste en las relaciones con los clientes y proveedores, los nombres de los productos, las marcas registradas y la reputación o imagen de la empresa.

Se trata de una dimensión externa a la organización, aunque en el valor de las relaciones que la empresa entabla con sus clientes y otros stakeholders, como bien señala Sveiby $(1998 ; 2018)$, influyen las acciones que desarrollen los miembros de la organización, que son quienes inician y mantienen esas relaciones. Más aún, algunos autores han remarcado la importancia del capital estructural como soporte para establecer y sostener las relaciones con stakeholders externos (Molodchik et ál., 2014; Sardo y Serrasquiero, 2018). 
Por último, es importante mencionar que varios autores, al abordar la temática de las relaciones de la organización, en el marco conceptual del CI, han destacado la relevancia del capital social. Algunos, como Nahapiet y Ghoshal (1998), lo consideran como un componente autónomo que constituye una importante influencia en el desarrollo del cI. Estos autores lo conceptualizan como la red de relaciones que se dan entre los miembros de la organización, o que posee la organización misma como unidad social. Incluye también los recursos que se originan a partir de esas relaciones, y distingue tres dimensiones clave de este: la estructural, referida al patrón de conexiones entre los individuos; la relacional, vinculada a los tipos de relaciones personales que entre ellos se desarrollan, y la cognitiva, referida a los sistemas de valores y significados compartidos y a las creencias.

Otros autores, como Bueno et ál. (2008), lo reconocen como una categoría incluida dentro del capital relacional que incluye un conjunto de relaciones que mantiene la empresa con agentes externos (diferentes de los clientes, suministradores y aliados), los cuales no están directamente relacionados con el ámbito del negocio, como podrían ser las administraciones públicas o la sociedad en general, y que tienen que ver con el compromiso social, el desarrollo económico del entorno, la defensa del medio ambiente, la reputación corporativa, entre otras.

\section{Modelos y métodos para la identificación y medición del capital intelectual}

Tal como se ha destacado al referir a los aspectos que resultan definitorios del CI, la mayor parte de los elementos que involucra quedan fuera de los estados financieros de las empresas, por no cumplir con los requisitos establecidos para su reconocimiento contable. En efecto, elementos tales como

[...] la inversión en conocimiento, capital humano, innovación de nuevos productos, tecnología, redes de fidelidad con los consumidores, etc. son ejemplos de factores de naturaleza inmaterial que determinan el éxito empresarial pero que, con la regulación vigente, son excluidos de los balances 
empresariales debido, entre otras causas, a la "incertidumbre" existente respecto a la generación de beneficios económicos futuros. (Cañibano y Gisbert, 2006, p. 6)

Precisamente, el alto grado de incertidumbre asociado a los beneficios futuros esperados de ciertos intangibles es, tal como indica Hendriksen (1982), el problema fundamental que surge para su reconocimiento contable. A esto se suman las dificultades que entraña su medición fiable, junto a las que plantea la delimitación clara de su control o propiedad por parte de la empresa (Cañibano y Gisbert, 2007).

Son precisamente estas dificultades las que han generado importantes restricciones para el reconocimiento contable del CI, es decir, para el reconocimiento contable de elementos como el conocimiento de los empleados y otros aspectos relacionados con el capital humano de la empresa, las rutinas organizativas, la calidad de los procesos, productos y servicios, el capital tecnológico, la capacidad de innovación, las relaciones con los clientes, proveedores, inversores y otros stakeholders y las alianzas estratégicas que la empresa entable y mantiene con ellos, entre otros. Este ha sido un elemento común en los ordenamientos contables de la mayoría de los países y ha dado lugar a que solo unos pocos intangibles queden incluidos en los estados financieros dentro del rubro "activos intangibles" 4 , y que muchos importantes factores de naturaleza inmaterial, determinantes de la creación de valor empresarial, como los antes mencionados, queden

4 En el ámbito contable, la expresión "activos intangibles" es la habitualmente utilizada para hacer "referencia exclusivamente a aquellas inversiones de naturaleza intangible que, de acuerdo con las normas contables, pueden ser reconocidas como activos y, consiguientemente, pueden ser reflejadas en el balance de la empresa" (Cañibano et ál., 2002, p. 16). Dentro del rubro "activos intangibles" se distinguen dos categorías fundamentales que surgen de su clasificación de acuerdo con el criterio de identificabilidad (Belkaoui, 1992), a saber: plusvalía (conocida como "llave de negocio" en Argentina, como "fondo de comercio" en España y como "crédito mercantil" en otros países de Latinoamérica) y otros activos intangibles identificables, que son, además, las que las normas contables han diferenciado para regular su tratamiento. 
fuera de dichos informes, por no cumplir con los requisitos previstos para su reconocimiento contable (Ficco, 2019).

Aun cuando las Normas Internacionales de Información Financiera (NIIF) $)^{5}$, emitidas por el International Accounting Standards Board (IASB), "han favorecido una mayor flexibilidad en el reconocimiento de activos de naturaleza intangible, principalmente, luego de las revisiones acaecidas a partir de 2004" (Ficco, 2019, p. 67), la postura sigue siendo restrictiva en cuanto a su inclusión en los estados financieros (Ficco y Werbin, 2017). Así, tal y como señalan Cañibano y Gisbert (2006), "los cambios son aún conservadores si tenemos en cuenta que, en el entorno económico actual, los activos materiales han dejado paso a los intangibles como principal fuente de generación de beneficios" (p. 6).

Concretamente, las NIIF del IASB requieren la posibilidad de obtención de beneficios económicos futuros y la medición confiable para el reconocimiento de un activo intangible, lo que se encuentra en línea con los requisitos generales de reconocimiento de cualquier activo. La NIC 38 (IASB, 2018) agrega también el requisito de identificabilidad, que tiene especial importancia, tal como remarcan Cañibano y Gisbert (2006), en las combinaciones de empresas, con el fin de diferenciar los activos intangibles de la empresa adquirida, de la plusvalía en su conjunto. En lo que respecta a los activos intangibles identificables, la NIC 38 (IASB, 2018) explicita ciertos conceptos que no pueden ser reconocidos como activos, como es el caso

5 Actualmente, las NiIf se utilizan en gran parte del mundo como base para la preparación de estados financieros, en virtud de un proceso expansivo de adopción iniciado a comienzos de este siglo. Este proceso, aunque no ha sido idéntico en todos los países, ha implicado, en general, que la mayoría de los países requieran la aplicación obligatoria de las NiIf para las empresas cotizantes en las bolsas de valores. Pero, además, ha dado lugar a reformas encaradas por muchos países para hacer converger la normativa local con las NIIF, tanto por parte de aquellos que han mantenido sus propias normas pero que ahora pueden decir que las mismas están armonizadas con las NIIF, como por parte de aquellos que han establecido la obligatoriedad en la aplicación de NIIF para las empresas cotizantes y quieren evitar una brecha entre la información contable de estas respecto de las no cotizantes (Deloitte, 2016; Ficco, 2018). 
de los desembolsos vinculados a la investigación u otros realizados para el desarrollo interno de marcas, listas de clientes u otras partidas similares que se hayan generado internamente, que deben imputarse a resultados, al igual que los costos de puesta en marcha de operaciones, los desembolsos por actividades formativas y por publicidad y otras actividades promocionales y los desembolsos por reubicación o reorganización parcial o total de la empresa.

Con relación a la plusvalía, se admite solo el reconocimiento de la que fuera adquirida en una combinación de negocios. La NIC 38 (IASB, 2018), expresamente, indica que la plusvalía generada internamente "no se reconocerá como un activo" (párr. 48).

Este marco regulatorio restrictivo para el reconocimiento de elementos de carácter intangible deriva de la peculiar naturaleza de estos elementos, que determina que los organismos reguladores definan su tratamiento contable dando prioridad a la fiabilidad de la información por sobre su relevancia (Cañibano et ál., 1999; Lev et ál., 2005). Así, por la aplicación del principio de prudencia (o conservadurismo), quedan fuera de los estados financieros muchos de los intangibles que componen el ci de las empresas (García y Mora, 2004; Pérez y Tangarife, 2013).

Por ello, y como una forma de paliar esta carencia de la contabilidad financiera, se han ido diseñando distintos métodos y modelos que brindan información sobre el cr, lo cual permite su identificación y medición. En este sentido, cabe aclarar, siguiendo a Vázquez y Bongianino (2005), que la idea de medición adquiere un sentido amplio y va más allá de los criterios contables, involucrando, en muchos casos, mediciones en términos relacionales de aspectos significativos.

Los primeros intentos para construir las bases para medir el ci se realizaron a finales de los ochenta (García et ál., 2006), de los cuales se destaca la labor realizada por Sveiby, en Suecia, que queda plasmada en la publicación del libro Balance invisible. Ya durante la década de los noventa, empresas como Celemi y Skandia comienzan a informar sobre su cI hacia el exterior 
y se desarrollan también las primeras iniciativas sistemáticas para medir y gestionar el CI, entre ellas, el Cuadro de Mando Integral (Kaplan y Norton, 1992), el Navegador de Skandia (Edvinsson, 1997) y el Monitor de Activos Intangibles (Sveiby, 1997).

Luego de estos primeros desarrollos se diseñaron otras propuestas, con una variedad de métodos y modelos muy amplia. Algunos apuntan a la medición del cr en forma global o a partir de algunos de sus componentes; otros se enfocan en la medición de los resultados de su gestión. Ello tiene que ver con la finalidad para la cual se han ideado, en tanto algunos modelos han sido construidos para ayudar a la gestión de los intangibles a nivel interno de las organizaciones mientras que otros, en cambio, pretenden hacer más accesible la información sobre CI a los stakeholders externos, principalmente a los inversores.

Muchos son los autores que han realizado esfuerzos para proveer una visión de los diferentes métodos existentes para la medición del CI. Hace más de una década, Andriessen (2004) presentaba la revisión y análisis de 25 métodos diferentes. Pero la lista no se cierra allí, ya que, ante la falta de aceptación generalizada de una solución única para efectuar tal medición, se sigue ampliando en la medida que se van desarrollando nuevas alternativas posibles con propósitos diversos. En otro trabajo de revisión realizado más recientemente (Ramanauskaite y Rudžionienè, 2013), se han identificado más de 60 modelos para la medición del cr.

Aquí se presentan los que han tenido mayor difusión, considerando principalmente aquellos que han sido pioneros en la temática, para el efecto de dejar plasmadas las principales alternativas disponibles para lograr la identificación y medición del cr. Estos métodos se presentan clasificados en base al clásico criterio propuesto por Sveiby (2010), quien distingue entre los que realizan mediciones en unidades monetarias, también llamados métodos financieros (Andriessen, 2004), y aquellos que son no monetarios.

Dentro de los métodos financieros Sveiby (2010) separa métodos de capitalización de mercado (МСм), métodos basados en la rentabilidad de 
los activos $\left(\mathrm{MBRA}^{6}\right)$ y métodos directos (DIC) y, dentro de los no monetarios, incluye a los métodos Scorecard (sc). La tabla 1 presenta una descripción sucinta de cada una de estas categorías.

Tabla 1. Propuesta de clasificación de los modelos y métodos para la medición del CI

\begin{tabular}{|l|l|}
\hline \multicolumn{1}{|c|}{ Métodos financieros } & \multicolumn{1}{c|}{ Medición en unidades monetarias } \\
\hline $\begin{array}{l}\text { Métodos de capitalización } \\
\text { de mercado (MCM) }\end{array}$ & $\begin{array}{l}\text { Calculan el valor monetario del ci como diferencia } \\
\text { entre la capitalización bursátil de la empresa } \\
\text { (cantidad total de acciones en circulación por su } \\
\text { precio de cotización) y su patrimonio neto contable. }\end{array}$ \\
\hline $\begin{array}{l}\text { Métodos basados en la } \\
\text { rentabilidad de los activos } \\
\text { (MBRA) }\end{array}$ & $\begin{array}{l}\text { Estiman el valor del cr en base a la rentabilidad de } \\
\text { los activos de la empresa, el rendimiento promedio } \\
\text { de la industria a la que pertenece y el importe de los } \\
\text { activos tangibles. }\end{array}$ \\
\hline Métodos directos (DIC) & $\begin{array}{l}\text { Estiman el valor monetario del ci a partir de } \\
\text { la identificación y medición de algunos de sus } \\
\text { componentes. Normalmente involucran modelos de } \\
\text { medición complicados, considerando solo algunos } \\
\text { pocos aspectos del cI. }\end{array}$ \\
\hline Métodos no financieros & Medición en unidades no monetarias \\
\hline $\begin{array}{l}\text { Métodos Scorecard (sc) } \\
\text { (basados en indicadores) }\end{array}$ & $\begin{array}{l}\text { Trabajan a partir de la identificación de los } \\
\text { componentes del cI, pero sin realizar mediciones en } \\
\text { términos monetarios. Proveen indicadores. }\end{array}$ \\
\hline
\end{tabular}

Fuente: elaboración propia, con base en Sveiby (2010) y Andriessen (2004).

Los métodos MCM y MBRA, que trabajan a nivel organizacional (Sveiby, 2010) aportando mediciones monetarias para el CI, son útiles en procesos de fusión y adquisición de empresas, en valuaciones a nivel del mercado de capitales y para comparar empresas pertenecientes al mismo ramo de actividad. Además, como algunos de ellos se basan en información contable,

6 Sveiby (2010) emplea la sigla ROA para referir a estos métodos. No obstante, se ha considerado más apropiado usar la sigla MBRA para evitar la confusión entre las distintas mediciones involucradas en este conjunto de métodos con el indicador económico de rentabilidad de los activos, habitualmente conocido como ROA. 
tienen la ventaja de que son más fáciles de implementar y de comunicar. Sin embargo, al considerar solo elementos que pueden ser expresados en términos monetarios y al trabajar a nivel general de la organización, dejan de lado mucha información relevante sobre el cr que puede ser de gran utilidad para la gestión de los intangibles a nivel interno, lo que hace que estos métodos tengan un uso limitado para esos fines.

En las tablas 2 y 3 se brinda una idea sucinta de las propuestas que han tenido mayor difusión dentro de las tipologías MCM y MBRA. Los distintos modelos y métodos se presentan, con la especificación de su nombre y abreviatura - si existiera - y con indicación del autor o autores que lo han ideado y del año de su creación o primera aparición en una publicación.

Tabla 2. Modelos y métodos MCM

\begin{tabular}{|l|l|}
\hline \multicolumn{1}{|c|}{ Modelos y métodos } & \multicolumn{1}{c|}{ Características fundamentales } \\
\hline $\begin{array}{l}\text { Ratio "q" de Tobin } \\
\text { (Tobin's "q") }\end{array}$ & $\begin{array}{l}\text { "q" es la relación entre el valor de mercado } \\
\text { de la empresa y el costo de reposición de sus } \\
\text { activos. El uso de este ratio se basa en la idea } \\
\text { de que, si "q" es mayor que 1 y mayor que la } \\
\text { "q" de los competidores, la empresa tiene la } \\
\text { capacidad de producir beneficios más altos que } \\
\text { otras compañías similares, por lo que tiene algo } \\
\text { intangible su ci que le otorga una ventaja. }\end{array}$ \\
\hline $\begin{array}{l}\text { El balance invisible } \\
\text { (The Invisible Balance Sheet) }\end{array}$ & $\begin{array}{l}\text { La diferencia entre el valor bursátil de una } \\
\text { empresa y su valor contable revela un "balance in- } \\
\text { visible", que puede explicarse por la existencia de } \\
\text { tres "familias" interrelacionadas de capital: capital } \\
\text { humano, capital estructural y capital de clientes. } \\
\text { Provee más de 35 indicadores clave. }\end{array}$ \\
\hline $\begin{array}{l}\text { Ronrad Group, 1989) } \\
\text { valor en libros } \\
\text { (Market- to-book ratio - M/B } \\
\text { ratio) } \\
\text { (Stewart, 1997) }\end{array}$ & $\begin{array}{l}\text { Plantea la relación entre el valor de mercado } \\
\text { de la empresa (producto entre la cantidad total } \\
\text { de acciones en circulación por su precio de } \\
\text { cotización) y su valor contable (patrimonio neto } \\
\text { contable). } \\
\text { Se basa en la idea de que el ci de una empresa } \\
\text { puede representarse por la diferencia entre esos } \\
\text { dos valores. }\end{array}$ \\
\hline
\end{tabular}




\begin{tabular}{|l|l|}
\hline \multicolumn{1}{|c|}{ Modelos y métodos } & \multicolumn{1}{c|}{ Características fundamentales } \\
\hline $\begin{array}{l}\text { Valor de mercado asignado } \\
\text { por el inversor } \\
\text { (Investor assigned market value }\end{array}$ & $\begin{array}{l}\text { Considera que el verdadero valor de la empresa } \\
\text { es su valor de mercado, es decir, el valor creado/ } \\
\text { asignado por los inversores y propone dividir } \\
\text { - IAMV) }\end{array}$ \\
este valor en capital tangible más la suma de \\
otrondfield, 1998) & sostenible. \\
\hline
\end{tabular}

Fuente: elaboración propia, con base en Sveiby (2010), Vázquez y Bongianino (2005), Bontis (2001) y Luthy (1998).

Los métodos expuestos en la tabla 2, al basarse en la diferencia entre el valor de mercado de la empresa y su valor en libros, permiten determinar una medida para el cı que representa la del conjunto de elementos intangibles que el mercado valora pero que están "ocultos", por no estar reflejados en los estados financieros de las empresas. En este sentido, y aun cuando proporcionan un valor global para el cI, podría decirse que este valor refleja el efecto holístico de la interacción de los distintos componentes del cr, lo que da lugar a un valor superior al que resultaría de la suma de los valores individuales de cada uno de ellos (Forte et ál., 2017; Van der Meer-Kooistra y Zijlstra, 2001).

Tabla 3. Modelos y métodos MBRA

\begin{tabular}{|c|c|}
\hline Modelos y métodos & Características fundamentales \\
\hline $\begin{array}{l}\text { Valor económico } \\
\text { agregado } \\
\text { (Economic Value } \\
\text { Added, EVA) } \\
\text { (Stern Stewart y Co., } \\
1989 \text { ) }\end{array}$ & $\begin{array}{l}\text { Es una magnitud monetaria que utiliza las cifras contables } \\
\text { de la ganancia y el activo corregidas, junto con el costo } \\
\text { del capital. Se calcula como diferencia entre la ganancia } \\
\text { operativa neta (antes de costos financieros explícitos y } \\
\text { después de impuestos) y el cargo por el capital empleado } \\
\text { en dichas operaciones, el cual se calcula multiplicando } \\
\text { la tasa de costo promedio ponderado del capital por el } \\
\text { capital total invertido (activo corregido promedio, neto de } \\
\text { pasivos operativos). La idea implícita en el eva es que los } \\
\text { accionistas deben obtener una rentabilidad que compense } \\
\text { el riesgo asumido y, en caso de que el Eva sea positivo, los } \\
\text { accionistas no solo habrán logrado compensar el riesgo, } \\
\text { sino que, además, se está creando valor. }\end{array}$ \\
\hline
\end{tabular}


principales alternativas para su identificación y medición

\begin{tabular}{|c|c|}
\hline Modelos y métodos & Características fundamentales \\
\hline $\begin{array}{l}\text { Valor intangible } \\
\text { agregado } \\
\text { (Calculated Intangible } \\
\text { Value - CIV) } \\
\text { (Stewart, 1997) }\end{array}$ & $\begin{array}{l}\text { Permite calcular el valor de mercado de los intangibles } \\
\text { que no aparecen en los estados financieros, calculando el } \\
\text { exceso de retorno sobre los activos fijos y utilizando luego } \\
\text { esta medida para determinar la proporción de retorno } \\
\text { atribuible a los intangibles. } \\
\text { Se basa en el supuesto de que las ganancias de una } \\
\text { empresa, mayores a las de la industria, resultan de su CI. Y } \\
\text { se utiliza como indicador de la capacidad de la empresa de } \\
\text { usar sus recursos intangibles para que se generen ventajas } \\
\text { competitivas. }\end{array}$ \\
\hline $\begin{array}{l}\text { Coeficiente de } \\
\text { valor agregado } \\
\text { intelectual } \\
\text { (Value Added } \\
\text { Intellectual Coefficient, } \\
\text { VAIC) } \\
\text { (Pulic, 1998) }\end{array}$ & $\begin{array}{l}\text { Mide la eficiencia en la creación de valor, tanto del CI como } \\
\text { del capital físico. El cálculo de la eficiencia en el uso del CI } \\
\text { (ICE) se realiza de la siguiente forma: ICE = HCE + SCE, lo } \\
\text { que representa la contribución del capital humano y del } \\
\text { estructural, de manera conjunta, a la creación de valor; } \\
\text { siendo HCE el indicador de eficiencia del capital humano } \\
\text { y SCE el indicador de eficiencia del capital estructural. De } \\
\text { forma desagregada, ICE = VA/HU + ST/VA; siendo VA el } \\
\text { valor añadido generado por la empresa, HU el importe de } \\
\text { los gastos de personal y sT la diferencia entre VA y HU. }\end{array}$ \\
\hline $\begin{array}{l}\text { Beneficios } \\
\text { del capital de } \\
\text { conocimiento } \\
\text { (Knowledge Capital } \\
\text { Earnings - KCE) } \\
\text { (Lev, 1999) }\end{array}$ & $\begin{array}{l}\text { La metodología identifica la proporción del beneficio que } \\
\text { corresponde a los activos intangibles. Estos "beneficios del } \\
\text { capital de conocimiento" se calculan como una porción de } \\
\text { las ganancias normalizadas (promedio de la industria de } 3 \\
\text { años y estimaciones futuras de analistas) que se encuentran } \\
\text { por encima y por debajo de los beneficios esperados } \\
\text { atribuibles a los activos reconocidos contablemente. Es } \\
\text { decir, son los beneficios que no están relacionados con las } \\
\text { ganancias que deberían dar los activos reconocidos. }\end{array}$ \\
\hline
\end{tabular}

Fuente: elaboración propia con base en Sveiby (2010), Vázquez y Bongianino (2005); Bontis (2001) y Luthy (1998).

Los métodos DIC y SC son, en general, más apropiados para los fines de gestión del cr que los anteriormente presentados, en la medida que brindan información sobre sus distintos componentes, lo que permite tener una visión más acabada de la empresa. Las tablas 4 y 5 muestran una breve descripción de las propuestas más difundidas dentro de cada estas categorías. 
Tabla 4. Modelos y métodos DIC

\begin{tabular}{|c|c|}
\hline Modelos y métodos & Características fundamentales \\
\hline $\begin{array}{l}\text { Costos y contabilidad de } \\
\text { recursos humanos } \\
\text { (Human Resource Costing y } \\
\text { Accounting, HRCA) } \\
\text { (Flamholtz, 1985) } \\
\text { (Gröjer y Johanson, 1996) }\end{array}$ & $\begin{array}{l}\text { Eric Flamholtz, el pionero en contabilidad } \\
\text { de recursos humanos, desarrolló una serie } \\
\text { de métodos para calcular el valor de los } \\
\text { recursos humanos. } \\
\text { En } 1996 \text { Gröjer y Johanson sugirieron } \\
\text { el concepto de costos y contabilidad de } \\
\text { recursos humanos y presentaron un } \\
\text { método para el cálculo del impacto oculto } \\
\text { de los costos relacionados con los recursos } \\
\text { humanos en los beneficios de una empresa, } \\
\text { de modo que se ajustaran las cuentas de } \\
\text { pérdidas y ganancias con base al total de } \\
\text { costos relacionados con el personal. }\end{array}$ \\
\hline $\begin{array}{l}\text { Techonology broker } \\
\text { (Brooking, 1996) }\end{array}$ & $\begin{array}{l}\text { Considera que el ci de la empresa tiene } \\
\text { cuatro componentes principales: activos } \\
\text { centrados en el ser humano, activos de } \\
\text { propiedad intelectual, activos de mercado } \\
\text { y activos de infraestructura, cada uno } \\
\text { de los cuales son examinados a través de } \\
\text { cuestionarios específicos de auditoría. } \\
\text { Ofrece, además, tres métodos para calcular } \\
\text { el valor monetario del ci identificado a } \\
\text { través de dicha auditoría. }\end{array}$ \\
\hline $\begin{array}{l}\text { Citation, Weighted Patents } \\
\text { (Dow Chemical, 1996) }\end{array}$ & $\begin{array}{l}\text { Utiliza distintos indicadores de } \\
\text { intangibles que son resumidos en un } \\
\text { "factor tecnológico" que es estimado para } \\
\text { identificar el impacto de los esfuerzos } \\
\text { de I+D que conducen a la creación de } \\
\text { propiedad intelectual. }\end{array}$ \\
\hline $\begin{array}{l}\text { Contabilidad para el futuro } \\
\text { (Accounting for the Future, AFTF) } \\
\text { (Nash, 1998) }\end{array}$ & $\begin{array}{l}\text { AFTF es el valor actualizado de todos los } \\
\text { flujos netos de caja, descontados al costo de } \\
\text { mercado de capital. } \\
\text { La diferencia entre el AFTF al final del } \\
\text { período proyectado menos el del comienzo } \\
\text { del periodo es el valor añadido o creado } \\
\text { durante este. }\end{array}$ \\
\hline
\end{tabular}




\begin{tabular}{|c|c|}
\hline Modelos y métodos & Características fundamentales \\
\hline $\begin{array}{l}\text { Metodología de valoración } \\
\text { inclusiva } \\
\text { (Inclusive valuation methodology } \\
\text { (McPherson, 1998)- IVM) }\end{array}$ & $\begin{array}{l}\text { Usa jerarquías de indicadores ponderados } \\
\text { que se combinan y se enfoca en valores } \\
\text { relativos en lugar de valores absolutos. } \\
\text { Valor agregado combinado = valor agregado } \\
\text { monetario combinado con el valor agregado } \\
\text { intangible. }\end{array}$ \\
\hline $\begin{array}{l}\text { The value explorer } \\
\text { (Andriessen y Tiessen, 2000) }\end{array}$ & $\begin{array}{l}\text { Metodología contable que define y asigna } \\
\text { valor a las competencias esenciales de la } \\
\text { empresa clasificadas en cinco tipos: activos } \\
\text { y dotaciones; habilidades y conocimiento } \\
\text { tácito, valores y normas; tecnología y } \\
\text { conocimiento explícito y procesos primarios } \\
\text { y de gestión. } \\
\text { Determina también la contribución de cada } \\
\text { competencia a los beneficios brutos de la } \\
\text { empresa y realiza una proyección futura de } \\
\text { resultados. }\end{array}$ \\
\hline
\end{tabular}

Fuente: elaboración propia, a partir de Sveiby (2010), Vázquez y Bongianino (2005), Bontis (2001), y Luthy (1998)

Como se puede apreciar en la tabla 4, los modelos DIC apuntan a determinar un valor agregado para el CI a partir de la estimación de ciertos componentes específicos del mismo. Por ello, algunos autores los incluyen dentro del enfoque de medición del cI "basado en componentes" (Ginesti et ál., 2018). No obstante, es necesario destacar que este enfoque ha recibido importantes críticas. Por un lado, debido a la dificultad que plantea su implementación en la práctica, por la falta de información completa y confiable para medir los componentes individuales del cI. Por otro lado, porque no considera el efecto que produce la interacción sinérgica de los distintos componentes del ci sobre su valor total (Forte et ál., 2017; Mouritsen, 2009). En cambio, los modelos sc (tabla 5) no tiene como objetivo prioritario el de proveer un valor para el CI, sino que apuntan a describirlo a partir de un conjunto de indicadores financieros y no financieros. 
Tabla 5. Modelos y métodos sC

\begin{tabular}{|c|c|}
\hline Modelos y métodos & Características fundamentales \\
\hline $\begin{array}{l}\text { Cuadro de mando integral } \\
\text { (Balanced Score Card) } \\
\text { (Kaplan y Norton, 1992) }\end{array}$ & $\begin{array}{l}\text { Traduce la estrategia y la misión de la empresa } \\
\text { en un conjunto de indicadores financieros y } \\
\text { no financieros referidos a cuatro perspectivas: } \\
\text { financiera, de clientes, de procesos internos y de } \\
\text { aprendizaje y crecimiento. }\end{array}$ \\
\hline $\begin{array}{l}\text { Navegador Skandia } \\
\text { (Skandia Navigator) } \\
\text { (Edvinsson, 1994) }\end{array}$ & $\begin{array}{l}\text { Indicadores de medida absoluta y de eficiencia } \\
\text { referidos a cinco áreas de enfoque: financiero, } \\
\text { humano, clientes, procesos y renovación y } \\
\text { desarrollo. }\end{array}$ \\
\hline $\begin{array}{l}\text { Índice de cI } \\
\text { (IC-Index) } \\
\text { (Ross, Ross, Dragonetti y } \\
\text { Edvinsson, 1997) }\end{array}$ & $\begin{array}{l}\text { Índice global que consolida los indicadores } \\
\text { individuales que representan los distintos } \\
\text { componentes y propiedades del cI, el cual es } \\
\text { considerado en dos categorías: capital humano y } \\
\text { capital estructural. Además, relaciona cambios en } \\
\text { el índice con cambios en el valor de mercado de la } \\
\text { empresa. }\end{array}$ \\
\hline $\begin{array}{l}\text { Monitor de activos } \\
\text { intangibles } \\
\text { (Intangible Asset Monitor) } \\
\text { (Sveiby, 1997) }\end{array}$ & $\begin{array}{l}\text { Indicadores para medir cuatro aspectos de la } \\
\text { creación de valor: crecimiento, renovación, } \\
\text { utilización/eficiencia y reducción del riesgo/ } \\
\text { estabilidad, para tres categorías de activos } \\
\text { intangibles: estructura interna, estructura externa y } \\
\text { competencias de los empleados. }\end{array}$ \\
\hline $\begin{array}{l}\text { Modelo Intellect } \\
\text { (Euroforum, 1998) }\end{array}$ & $\begin{array}{l}\text { Indicadores de presente y futuro para medir/ } \\
\text { evaluar los distintos elementos del cI agrupados en } \\
\text { tres bloques: capital humano, capital estructural } \\
\text { (dividido en capital organizativo y tecnológico) y } \\
\text { capital relacional (dividido en capital negocio y } \\
\text { social). }\end{array}$ \\
\hline $\begin{array}{l}\text { Value Chain Scoreboard } \\
\text { (Lev, 2000) }\end{array}$ & $\begin{array}{l}\text { Sistema de indicadores no financieros organizados } \\
\text { en tres categorías según el ciclo de desarrollo de los } \\
\text { productos: descubrimiento/aprendizaje, ejecución } \\
\text { y comercialización. Brinda información sobre las } \\
\text { distintas capacidades de la empresa para obtener } \\
\text { éxito en la creación de valor económico, y se centra } \\
\text { en el proceso de innovación. }\end{array}$ \\
\hline
\end{tabular}




\begin{tabular}{|c|c|}
\hline Modelos y métodos & Características fundamentales \\
\hline $\begin{array}{l}\text { Directrices Meritum } \\
\text { (Cañibano et ál., 2002) }\end{array}$ & $\begin{array}{l}\text { Sistema de indicadores que distingue entre recursos } \\
\text { intangibles - como activos y capacidades- } \\
\text { (noción estática) y actividades intangibles (noción } \\
\text { dinámica). Considera al cr integrado por: capital } \\
\text { humano, capital estructural y capital relacional. }\end{array}$ \\
\hline $\begin{array}{l}\text { Guías danesas } \\
\text { (Mouritzen, Bukh et ál., } \\
2003 \text { ) }\end{array}$ & $\begin{array}{l}\text { Recomendaciones acerca de cómo las empresas } \\
\text { deben informar sobre sus intangibles. Proponen que } \\
\text { los informes de ci consistan en: una narrativa de } \\
\text { conocimiento; un conjunto de desafíos de gestión; } \\
\text { una serie de iniciativas e indicadores relevantes. En } \\
\text { cada una de esas líneas se debe brindar información } \\
\text { sobre el ci agrupado en cuatro tipos: clientes, } \\
\text { trabajadores, procesos y tecnologías. }\end{array}$ \\
\hline
\end{tabular}

Fuente: elaboración propia con base en Sveiby (2010), Vázquez y Bongianino (2005), Bontis (2001) y Luthy (1998).

Los modelos y métodos expuestos en las tablas 2 a 5 son aquellas que han alcanzado mayor difusión y las que más han influido en los intentos de medición del cr. Muchos de ellos han servido de base para generar nuevas propuestas que apuntan a dar respuesta a cuestiones no contempladas, así como a la especificidad de ciertas organizaciones - como las no lucrativas o las pertenecientes al sector público- o de ciertos niveles, como es el nivel macroeconómico, con los desafíos que plantea la medición y gestión de intangibles a nivel de naciones, regiones o ciudades ${ }^{7}$.

$7 \quad$ Así, por solo mencionar algunas de las propuestas más recientes y su orientación, cabe citar la de Sydler et ál.(2013) que permite medir el capital intelectual en términos monetarios y evaluar su impacto en la rentabilidad de la empresa; la de Gu y Lev (2011), que desarrollan un método para estimar el valor de los intangibles, basado en un enfoque económico de la función de producción, de utilidad tanto para la gestión como para los inversores externos; el índice de capital intelectual regional de Schiuma, et ál. (2008), el reporte de capital Intelectual para universidades (ICU Report) desarrollado por Sánchez, Elena y Castrillo (2007) y el modelo para la gestión del capital intelectual universitario desarrollado a partir de un modelo cubano con la participación de 9 universidades iberoamericanas de Argentina, Bolivia, Cuba y México (Borrás y Prieto, 2019). 
No obstante, resulta importante señalar, una vez más, que estos métodos y modelos de medición cumplen una función muy significativa a la hora de complementar la información que brindan los estados financieros sobre los recursos y capacidades intangibles que componen el ci de las empresas, dada la la dificultad que presentan estos elementos para satisfacer los requisitos de reconocimiento que establecen las normas contables actualmente vigentes. En este sentido, pueden ser de gran utilidad "en el frente interno, aportando información relevante para la toma de decisiones de gestión de la empresa, y en el frente externo, mejorando la información referida al valor de la empresa que se presenta a terceros" (Vázquez y Bongianino, 2005, p. 53).

Precisamente, la revelación, por parte de las empresas, de información adicional a la que proveen los estados financieros tradicionales parece erigirse como la solución a las deficiencias de dichos informes en relación con el ci (Dumay, 2016). Así, en el actual contexto, "la información en la memoria o en los informes de capital intelectual, se presenta como alternativa para mejorar la información suministrada al inversor sobre los recursos y capacidades intangibles de la empresa" (Cañibano y Gisbert, 2006, p. 6). De hecho, la propia NIC 38 del IASB, desde sus orígenes, se ha destacado por acentuar los aspectos informativos, planteando mayores exigencias y recomendaciones en cuanto a la información a revelar sobre los recursos intangibles más significativos y controlados por la empresa que, por no cumplir con los criterios establecidos en la norma, no aparecen en el estado de situación financiera.

\section{Conclusiones}

En el presente estudio se ha revisado la literatura que ha abordado el concepto y la constitución del cI, junto a aquella que se ha ocupado de los métodos y modelos para su identificación y medición. La revisión y análisis realizados han tenido como propósito fundamental identificar y definir los rasgos característicos del concepto junto a los distintos elementos y categorías que lo integran, así como también los métodos y modelos de medición que han alcanzado mayor difusión. 
Para dar cumplimiento a tal objetivo se ha adoptado un enfoque amplio e integrador, que implicó la revisión de las aportaciones de autores de diferentes países, incluyendo las de aquellos que han sido pioneros y creadores de los trabajos seminales en la temática, como también las que surgen de investigaciones más recientes y que reflejan su evolución a través del tiempo.

La revisión realizada deja en claro que existe una extensa literatura en torno al concepto de CI, aunque también revela que no se ha logrado una definición de aceptación generalizada. Se trata, más bien, de un concepto en evolución que se ha configurado y se sigue desarrollando desde diferentes enfoques y perspectivas. No obstante, sobre la base de las principales características que están presentes en la mayoría de los conceptos elaborados, se puede afirmar que el CI refiere al conjunto de elementos intangibles (recursos, capacidades y actividades) relacionados entre sí, entre los que destaca el conocimiento disponible, tanto a nivel individual como organizativo. Aquellos están en cierta medida ocultos, por no estar reflejados en los estados financieros elaborados con base en la normativa vigente; no obstante, permiten a la empresa funcionar, en combinación con los demás recursos inherentes, con una siendo fuente de ventaja competitiva y de creación de valor.

La literatura muestra, además, una variada gama de elementos que se han ido explicitando como integrantes del CI. Se trata de elementos de diversa índole, pero que pueden agruparse en una serie de categorías que permiten elaborar clasificaciones del cr. En este sentido, aunque también se advierte la existencia de distintas propuestas, existe un amplio consenso en lo atinente a la clasificación del cr en capital humano, capital estructural y capital relacional. Esta división permite distinguir tres grandes bloques que aludirían, respectivamente, al conocimiento individual que reside en los trabajadores, al conocimiento que la empresa ha podido internalizar y que se refleja tanto a nivel de su estructura, procesos y cultura como en su capacidad de renovación, y al conocimiento existente en la organización que permite crear relaciones sólidas con su ámbito externo. 
Finalmente, la revisión realizada también revela la amplia variedad de propuestas diseñadas para identificar y medir el cı y, una vez más, la falta de consenso en torno a cuáles son las alternativas más apropiadas para efectuar tal medición, lo que se vincula, en gran parte, con la finalidad para la cual se han ideado, en tanto algunos modelos han sido construidos para ayudar a la gestión de los intangibles mientras que otros, en cambio, pretenden hacer más accesible la información sobre Ci a los stakeholders externos.

El panorama antes expuesto refleja que el ci es un tema de gran relevancia e interés para las empresas en el actual contexto de la economía del conocimiento, aunque se trata también de una temática compleja y multifacética cuyo abordaje se encuentra aún inconcluso y en permanente evolución. De este modo, el ci tiene aún múltiples aristas para ser abordadas en futuros trabajos, lo que plantea grandes desafíos que abren un importante campo para el desarrollo de nuevas investigaciones en esta línea.

\section{Referencias}

Andriessen, D. (2004). Making sense of intellectual capital: Designing a method for the valuation of intangibles. Oxford Elsevier Butterworth-Heinemann.

Azofra, V., Ochoa, M., Prieto, B. y Santidrián, A. (2017). Creando valor mediante la aplicación de modelos de capital intelectual. Innovar: Revista de Ciencias Administrativas y Sociales, 27(65), 25-38. Dor: https://doi.org/10.15446/ innovar.v27n65.64887

Barney, J. (1991). Firm resources and sustained competitive advantage. Journal of Management, 17(1), 99-120.

Belkaoui, A. (1992). Accounting Theory. Cambridge: Academic Press.

Bontis, N. (1998). Intellectual capital: An exploratory study that develops measures and models. Management Decision, 36(2), 63-76.

Bontis, N. (1999). Managing organizational knowledge by diagnosing intellectual capital: Framing and advancing the state of the field. International Journal of Technology Management, 18(5-8), 433-462. 
Bontis, N. (2001). Assessing knowledge assets: A review of the models used to measure intellectual capital. International Journal of Management Reviews, 3(1), 41-60.

Bontis, N., Chong, W. y Richardson, S. (2000). Intellectual capital and business performance in Malaysian industries. Journal of Intellectual Capital, 1(1), 85-100.

Bontis, N., Dragonetti, N., Jacobsen, K. y Roos, G. (1999). The knowledge toolbox: a review of the tools available to measure and manage intangible resources. European Management Journal, 17(4), 391-402.

Borrás, F. y Prieto, B. (2019). Sistemas de información universitarios para un futuro sostenible. Revista de la Asociación Española de Contabilidad y Administración de empresas, 127, 13-15.

Brooking, A. (1996). Intellectual Capital. International Thomson Business Press.

Bueno, E. (2003). Modelo Intellectus: Medición y Gestión del Capital Intelectual. Documento Intellectus. 5. CIC-IADE.

Bueno, E. y Murcia, C. (2018). Medición, gestión e información del capital intelectual: La experiencia del modelo intellectus. En A. López, J. Guimón y J. Salazar (Eds.), Innovación, capital intelectual y desarrollo económico (pp. 231-247). Madrid: UAm Ediciones.

Bueno, E., Salmador, M. y Merino, C. (2008). Génesis, concepto y desarrollo del capital intelectual en la economía del conocimiento: una reflexión sobre el Modelo Intellectus y sus aplicaciones. Estudios de Economía Aplicada, 26(2), 43-63.

Cabrita, M. y Bontis, N. (2008). Intellectual capital and business performance in the Portuguese banking industry. International Journal of Technology Management, 43(1-3), 212-237.

Cañibano, L. (2007). Algunos nuevos retos de la información contable-financiera: intangibles, internet y gestión de beneficios. Activos, 7(13), 89-115.

Cañibano, L., García, M. y Sánchez, M. (1999). La relevancia de los intangibles para la valoración y la gestión de empresas: Revisión de la literatura. Revista Española de Financiación y Contabilidad, 100, 17-88.

Cañibano L. y Gisbert A. (2006). Los intangibles en las Normas Internacionales de Información Financiera. Noticias de la Unión Europea, 259-260, 5-20.

Cañibano, L. y Gisbert, A. (2007). Los activos intangibles en el nuevo Plan General Contable. Revista del Instituto de Estudios Económicos, 2-3, 191-212. 
Cañibano, L., Sánchez, M. García, M. y Chaminade, C. (2002). Directrices para la gestión y difusión de información sobre intangibles (Informe de Capital Intelectual). Madrid: Fundación Airtel Móvil.

Carlucci, D. y Schiuma, G. (2007). Exploring intellectual capital concept in strategic management research. En L. Joia (Ed.), Strategies for Information Technology and Intellectual Capital: Challenges and Opportunities (pp. 10-28). Pensilvania: Idea Group.

Castilla, F. y Ruiz, C. (2014). Una revisión histórico-descriptiva de las empresas pioneras en el tratamiento de intangibles. Intangible Capital, 10(1), 125-154.

Dean, A. y Kretschmer, M. (2007). Can Ideas be Capital? Factors of Production in the Postindustrial Economy: A Review and Critique. Academy of Management Review, 32, 573-594.

Deloitte (2016). Guía rápida de las NIIF 2016. Consultado en https://www.iasplus. com/en/publications/spain/guia-rapida-ifrs-2016-spanish

Dumay, J. (2016). A critical reflection on the future of intellectual capital: From reporting to disclosure. Journal of Intellectual Capital, 17(1), 168-184.

Dumay, J., Guthrie, J. y Rooney, J. (2018). The critical path of intellectual capital. En J. Guthrie, J. Dumay, F. Riccieri y C. Nielsen (Eds.), The Routledge Companion to Intellectual Capital (pp. 21-39). Londres Routledge.

Edvinsson, L. (1997). Developing intellectual capital at Skandia. Long Range Planning, 30(3), 366-373.

Edvinsson, L. y Malone, M. (1997). Intellectual Capital. Realizing your company's true value by findings its hidden brainpower. Nueva York: HarperCollins Publishers.

Edvinsson, L. y Malone, M. (1999). El capital intelectual. Cómo identificar y calcular el valor de los recursos intangibles de su empresa. Madrid: Ediciones Gestión 2000.

Euroforum Escorial (1998). Medición del Capital Intelectual: Modelo Intelect. Madrid Instituto Universitario Euroforum Escorial.

Ficco, C. (2018). La relevancia valorativa de los activos intangibles y del capital intelectual en el mercado de capitales argentino [tesis doctoral]. Universidad Nacional de Córdoba, Argentina. 
Ficco, C. (2019). Los activos intangibles en la normativa contable argentina y en las normas internacionales de información financiera. Contabilidad y Auditoría, 50, 61-108.

Ficco, C. (2020). Relevancia valorativa de los activos intangibles y del capital intelectual: Una revisión de la literatura empírica. Revista Academia e Negocios, 6(1), en prensa.

Ficco, C. y Werbin, E. (2017). Los activos intangibles en la investigación contable orientada al mercado de capitales: revisión de la literatura empírica sobre su relevancia para la valoración de las empresas. Revista de Economía y Estadística, 55(1), 7-43.

Forte, W., Tucker, J., Matonti, G. y Nicolò, G. (2017). Measuring the intellectual capital of Italian listed companies. Journal of Intellectual Capital, 18(4), 710-732.

García, J. y Mora, A. (2004). El conservadurismo contable versus el reconocimiento de los activos intangibles: Efecto sobre el papel de la información contable en los mercados financieros. Análisis Financiero, 95, 14-27.

García, M., Simó, P. y Sallán, J. (2006). La evolución del capital intelectual y las nuevas corrientes. Intangible Capital, 2(13), 277-307.

Ginesti, G., Caldarelli, A. y Zampella, A. (2018). Exploring the impact of intellectual capital on company reputation and performance. Journal of Intellectual Capital, 19(5), 915-934.

Gogan, L., Rennung, F., Istis, G. y Drahici, A. (2014). A proposed tool for managing intellectual capital in small and medium size enterprises. Procedia Technology, 16, 728-736.

Gu, F. y Lev, B. (2011). Intangible assets: measurement, drivers, usefulness. En G. Schiuma. (ed.), Managing knowledge assets and business value creation in organizations: measures and dynamics (pp. 110-124). Pensilvania: IGI Global.

Hendriksen, E. (1982). Accounting Theory. Boston: Irwin.

Hudson, W. (1993). Intellectual capital: How to build it, enhance it, use it. John Wiley \& Sons.

Ilyin, D. (2014). The impact of intellectual capital on companies' performance: evidence from emerging markets. Korporativnye Finansy, 32(4), 46-66.

International Accounting Standards Board (2018). Norma Internacional de Contabilidad $N^{\circ}$ 38: Activos intangibles. Londres IASB. 
Kaplan, R. y Norton, D. (1992). The balanced scorecard. Measures that drive performance. Harvard Business Review, 70(1), 71-79.

Kianto, A., Andreeva, T. y Pavlov, J. (2013). The impact of intellectual capital management on company competitiveness and financial performance. Knowledge Management Research and Practice, 11, 12-22.

Kimouche, B. y Rouabhi, A. (2016). Intangibles and value relevance of accounting information: Evidence from UK companies. Jordan Journal of Business Administration, 12(2), 437-458.

Kujansivu, P. y Lönnqvist, A. (2007). Investigating the value and efficiency of intellectual capital. Journal of Intellectual Capital, 8(2), 272-287.

Lentjušenkova, O. y Lapina, I. (2016). The transformation of the organization's intellectual capital: from resource to capital. Journal of Intellectual Capital, 17(4), 610-631.

Lev, B. (2001). Intangibles: management, measurement and reporting. Washington D. C.: The Brookings Institution Press.

Lev, B. (2005). Intangible assets: concepts and measurements. Encyclopedia of Social Measurement, 2(1), 299-305.

Lev, B., Canibano, L. y Marr, B. (2005). An accounting perspective on intellectual capital. En B. Marr (ed.), Perspectives on intellectual capital (pp. 42-55). Elsevier.

López, M., Santanatoglia, J., Pedroni, F., Albanese, D. y Milanesi, G. (2013). Activos intangibles. Revisión del marco normativo contable nacional e internacional. Escritos Contables y de Administración, 4(2), 55-89.

Luthy, D. (1998). Intellectual capital and its measurement [ponencia]. Proceedings of the Asian Pacific Interdisciplinary Research in Accounting Conference (APIRA), Osaka, Japan.

Martín, G., Navas, J., López, P., y Delgado, M. (2010). El capital intelectual de la empresa. Evolución y desarrollo futuro. Economía Industrial, 378, 37-44.

Molodchik, M., Shakina, E. y Barajas, A. (2014). Metrics for the elements of intellectual capital in an economy driven by knowledge. Journal of Intellectual Capital, 15(2), 206-226.

Mouritsen, J. (2009). Classification, measurement and the ontology of intellectual capital entities. Journal of Human Resource Costing \& Accounting, 13(2), 154-162. 
Nahapiet, J. y Ghoshal, S. (1998). Social capital, intellectual capital, and the organizational advantage. Academy of Management Review, 23(2), 242-266.

Nonaka, I. (1991). The Knowledge-creating Company. Harvard Business Review, (noviembre-diciembre), 96-104.

Nonaka, I. y Takeuchi, H. (1995). The knowledge creating company: How Japanese companies manage the dynamics of innovation. Oxford: Oxford University Press.

Ochoa, M., Prieto, B. y Santidrián, A. (2010). Estado actual de los modelos de capital intelectual y su impacto en la creación de valor en empresas de Castilla y León. Revista de Investigación Económica y Social de Castilla y León, 13, 15-205.

Ordóñez de Pablos, P. (2003). Intellectual capital reporting in Spain: A comparative view. Journal of Intellectual Capital, 4(1), 61-81.

Pastor, D., Glova, J., Lipták, F. y Kovác, V. (2017). Intangibles and methods for their valuation in financial terms: Literature review. Intangible Capital, 13(2), 387-410.

Pérez, G. y Tangarife, P. (2013). Los activos intangibles y el capital intelectual: Una aproximación a los retos de su contabilización. Saber, Ciencia y Libertad, 8(1), 143-166.

Ramanauskaité, A. y Rudžionienė, K. (2013). Intellectual capital valuation: Methods and their classification. Ekonomika, 92(2), 79-92.

Roos, G., Roos, J., Dragonetti, N. y Edvinsson, L. (1997). Intellectual capital: Navigating in the new business landscape. New York: New York University Press.

Roos, G., Roos, J., Dragonetti, N. y Edvinsson, L. (2001). Capital Intelectual. Barcelona: Paidós.

Sánchez, P., Elena, S. y Castrillo, R. (2007). The ICU report: An Intellectual capital proposal for university strategic behavior [ponencia]. Institucional Management in Higher Education Conference, Paris, Francia.

Sardo, F. y Serrasqueiro, Z. (2018). Intellectual capital, growth opportunities, and financial performance in European firms: dynamic panel data analysis. Journal of Intellectual Capital, 19(4), 747-767.

Scafarto, V., Ricci, F. y Scafarto, F. (2016). Intellectual capital and firm performance in the global agribusiness industry: the moderating role of human capital. Journal of Intellectual Capital, 17(3), 530-552. 
Schiuma, G., Lerro, A. y Carlucci, D. (2008). The knoware tree and the regional intellectual capital index: An assessment within Italy. Journal of Intellectual Capital, 9(2), 283-300.

Sharma, N. (2012). Intangible assets: A study of valuation methods. BVIMR Management Edge, 5(1), 61-69.

Sierra, M. y Rojo, A. (2001). Los activos intangibles (capital intelectual) en contabilidad financiera. Madrid: Instituto de Contabilidad y Auditoría de Cuentas.

Simó, P. y Sallán, J. (2008). Capital intangible y capital intelectual: Revisión, definiciones y líneas de investigación. Estudios de Economía Aplicada, 26(2), 65-78.

Smriti, N. y Das, N. (2018). The impact of intellectual capital on firm performance: a study of Indian firms listed in cosPI. Journal of Intellectual Capital, 19(5), 935-964.

Stewart, T. (1998). La nueva riqueza de las organizaciones: El capital intelectual. Ediciones Granica.

Sveiby, K. (1989). The Invisible Balance Sheet. Key indicators for accounting, control and valuation of know-how companies. Toronto: The Konrad Group.

Sveiby, K. (1997). The new organizational wealth. Managing and measuring knowledge-based assets. California: Berrett- Koehler Publishers.

Sveiby, K. (1998). Measuring intangibles and intellectual capital. An emerging first standard. Consultado en http://www.sveiby.com/articles/EmergingStandard. html.

Sveiby, K. (2010). Methods for measuring intangible assets. Consultado en https:// www.sveiby.com/article/Methods-for-Measuring-Intangible-Assets.

Sveiby, K. (2018). Measuring intangibles: suggested indicators with cases.Consultado en https://www.sveiby.com/article/Measuring-Intangibles-SuggestedIndicators-with-Cases

Sydler, R., Haefliger, S. y Pruksa, R. (2013). Measuring intellectual capital with financial figures: Can we predict firm profitability? European Management Journal, 32(2), 244-259.

Tyskbo, D. (2019). Managers' views on how intellectual capital is recognized and managed in practice: A multiple case study of four Swedish firms. Journal of Intellectual Capital, 20(2), 282-304.

Torrent, J. (2016). La economía del conocimiento y el conocimiento de la economía. Oikonomics Revista de Economía, Empresa y Sociedad, 5, 26-32. 
Van der Meer-Kooistra, J. y Zijlstra, S. (2001). Reporting on intellectual capital. Accounting, Auditing \& Accountability Journal, 14(4), 456-476.

Vázquez, R. y Bongianino, C. (2005). Los Intangibles y la Contabilidad. Buenos Aires: Errepar.

Viedma, J. (2007). In search of an intellectual capital comprehensive theory. Electronic Journal of Knowledge Management, 5(2), 245-256.

Wernerfelt, B. (1984). A resource-based view of the firm. Strategic Management Journal, 5(2), 171-180.

Xu, J. y Wang, B. (2018). Intellectual capital, financial performance and companies' sustainable growth: evidence from the Korean manufacturing industry. Sustainability, 10(12), 4651.

Zambon, S. (2017). Intangibles and intellectual capital: An overview of the reporting issues and some measurement models. En P. Bianchi y S. Labory (eds.), The economic importance of intangible assets (pp. 165-196). Londres: Routledge. 